\title{
СРАВНИТЕЛЬНЫЙ АНАЛИЗ РЕАГЕНТОВ-ИНГИБИТОРОВ НАБУХАНИЯ ГЛИНИСТЫХ ОТЛОЖЕНИЙ, ПРИМЕНЯЕМЫХ НА МЕСТОРОЖДЕНИЯХ ВОСТОЧНОЙ СИБИРИ
}

\author{
Аверкина Елена Владимировна 1 \\ caverkina.l@yandex.ru \\ Шакирова Эльвира Венеровна ${ }^{1}$, \\ viva160@mail.ru
}
Николаева Маргарита Борисовна², margaritanik97@mail.ru

\author{
Климова Аина Александровна ${ }^{1}$, \\ cherdanceva94@yandex.ru \\ 1 Иркутский национальный исследовательский технический университет, \\ Россия, 664074, г. Иркутск, ул. Лермонтова, 83. \\ 2 Казанский федеральный университет, \\ Россия, 420008, г. Казань, ул. Кремлевская, 18.
}

\begin{abstract}
Актуальность. Подсолевой структурный комплекс месторождений Восточной Сибири включает в себя отложения ордовика, которые представлены преимущественно супесями, суглинками, глинами, алевролитами, мергелями и доломитами. Подсолевой комплекс состоит из аргиллитов, доломитов, известняков, а также их переслаивания. При бурении нефтяных скважин большое количество осложнений может вызвать набухание глинистых пород: прихват бурильного инструмента, кавернообразование, сальникообразование, расширение ствола скважины, потеря циркуляции и др. Буровой раствор должен обладать высокой инаибирующей способностью для максимального снижения интенсивности набухания. Этого свойства можно добиться специальньми реагентами-ингибиторами, которые являются основным компонентом ингибирующего бурового раствора.

Цель: исследовать ингибирующую способность линейки реагентов, которые представляют композиции аминов, полиамидов и ряда других соединений.

объект: буровой раствор, применяемый на месторождениях Восточной Сибири.

Mетоды. Для определения линейного набухания глины использовалась модель Linear Swellmeter OFITE, оnределяющая гидратирование или дегидратирование глин и глинистых пород путем измерения изменения линейных размеров образца из глины. Исследование по влиянию реагентов ингибиторов на реологические параметры бурового раствора проводилось с помощью традиционных методов.

Результаты и выводы. Установлено, что соли $\mathrm{MgCl}{ }^{*} 6 \mathrm{H}_{2} \mathrm{O}$ и NaCl, структурирующие молекулы воды, снижают набухание глинопорошка. Все исследуемые образцы ингибиторов в разной степени оказывают влияние на параметры бурового раствора, наиболее благоприятными для использования в пресном глинистом буровом растворе на основе бентонитовой немодифрицированной глины оказались Ингидол Б и Ингидол Sil. Остальные образцы также могут успешно использоваться при дальнейшей обработке раствора для регулирования реологических параметров и показателя фильтрации после проведенных дополнительных исследований.
\end{abstract}

Ключевые слова:

Буровой раствор, ингибиторы, глинистые отложения, Восточная Сибирь, реологические свойства.

\section{Введение}

Поддержание устойчивости стенок ствола скважины при бурении - одна из главных задач, которую нужно решать в интервалах залегания глинистых пород. Анализ строительства скважин, а также результатов исследований по буровым растворам за последнее время показывает [1-4], что растет количество осложнений в виде осыпей, обвалов, сужений ствола скважины, а также увеличиваются затраты времени и средств на их ликвидацию (до $50 \%$ аварийного времени) [5]. В этой связи одним из перспективных направлений успешного решения проблем строительства скважины тесно связано с совершенствованием технологии приготовления бурового раствора. Выбор типа, состава и свойств очистного агента для заданных горно-геологических условий (для бурения глинистых отложений) - задача комплексная, требующая научно обоснованного подхода.
Согласно имеющимся исследованиям [6-9] для сохранения устойчивости стенок ствола скважины при бурении в интервалах глинистых пород необходимо учитывать их состав, состояние и свойства, которые зависят от условий формирования и последующей историей развития. В этих условиях под влиянием внешних и внутренних факторов, в основном температуры и давления, формируются набухающие (пластичные) и ненабухающие (хрупкие) глинистые породы. Набухающие пластичные и водочувствительные глинистые породы ведут себя как высокопластичные тела, вызывают сужение ствола скважины и вываливаются. Ненабухающие хрупкие и пластично хрупкие способны растрескиваться и осыпаться в стволе скважины. Следовательно, прежде всего, необходимо классифицировать глинистые породы по характеру их разрушения [10] (табл. 1). 
Таблица 1. Классификация глинистых пород по характеру разрушения

Table 1. Classification of clay rocks by the nature of destruction

\begin{tabular}{|l|l|l|l|l|}
\hline $\begin{array}{l}\text { Группа пород } \\
\text { Rock group }\end{array}$ & $\begin{array}{l}\text { Подгруппа пород } \\
\text { Rock subgroup }\end{array}$ & \multicolumn{1}{|c|}{$\begin{array}{c}\text { Структурные контакты } \\
\text { Structural contacts }\end{array}$} & $\begin{array}{l}\text { Характер разрушения в } \\
\text { растворе } \\
\text { Nature of destruction in } \\
\text { solution }\end{array}$ \\
\hline $\begin{array}{l}\text { Скальные } \\
\text { Rocky }\end{array}$ & $\begin{array}{l}\text { Mетаморфические } \\
\text { Metamorphic }\end{array}$ & $\begin{array}{l}\text { Фазовые } \\
\text { Phase }\end{array}$ & $\begin{array}{l}\text { Сланцы } \\
\text { Shales }\end{array}$ & $\begin{array}{l}\text { Очень хрупкий } \\
\text { Very fragile }\end{array}$ \\
\hline $\begin{array}{l}\text { Полускальные } \\
\text { Half }\end{array}$ & - & $\begin{array}{l}\text { Аргиллиты, алевролиты } \\
\text { Мudstones, siltstones }\end{array}$ & $\begin{array}{l}\text { Хрупкий } \\
\text { Fragile }\end{array}$ \\
\hline $\begin{array}{l}\text { Связные } \\
\text { Connected }\end{array}$ & $\begin{array}{l}\text { Осадочные } \\
\text { Sedimentary }\end{array}$ & $\begin{array}{l}\text { Смешанные - коагуляционные, } \\
\text { переходные, фазовые } \\
\text { Mixed - coagulation, transitional, phase }\end{array}$ & $\begin{array}{l}\text { Супеси, суглинки, глины } \\
\text { Sandy loam, loam, clay }\end{array}$ & $\begin{array}{l}\text { Пластичный } \\
\text { (высокопластичный) } \\
\text { Plastic (high grade) }\end{array}$ \\
\hline
\end{tabular}

Из этого следует, что при выборе рецептуры бурового раствора необходимо учитывать особенности строения глинистых отложений.

\section{Объект и методика исследования}

В геологическом разрезе месторождений Восточной Сибири также встречаются глинистые породы. В состав надсолевого структурного комплекса включены отложения ордовика, которые представлены преимущественно супесями, суглинками, глинами, алевролитами, мергелями и доломитами. Глинистыми породами сложен и подсолевой комплекс, который состоит из аргиллитов, доломитов, известняков, а также их переслаивания.

Имеющийся производственный опыт бурения скважин на месторождениях Восточной Сибири показывает, что в большинстве случаев не удается предупредить нарушения устойчивости глинистых пород в околоствольном пространстве скважин [11]. Под влиянием фильтрата бурового раствора пластичные глинистые породы набухают, теряют устойчивость и переходят в буровой раствор, значительно ухудшая его качество.

Для бурения интервалов пластичных глин в основном применяются ингибирующие буровые растворы. Основное их назначение - снижение набухания и диспергации глин, минимизация влияния глинистого шлама на структурно-реологические и фильтрационные показатели раствора $[12,13]$.

На сегодняшний день отсутствует единый показатель оценки ингибирующей способности бурового раствора. В связи с этим, как показывает практика, ингибирующую способность характеризуют большим количеством различных показателей (увлажняющей способности, глиноемости, коллоидной фракции, наработки бурового раствора и т. д.) $[14,15]$. На исследовании процесса гидратации по коэффициентам набухания, размокания и скорости увлажнения $[16,17]$ базируются существующие методы оценки характера взаимодействия буровых растворов с глинистой породой.

В настоящей статье представлены результаты сравнительных испытаний ингибирующих добавок, оказывающих влияние на выбор типа, состава и технологии получения бурового раствора [18].

Для выполнения поставленной задачи в учебноисследовательской лаборатории буровых растворов и крепления скважин ИРНИТУ проведены лабораторные исследования ингибирующей способности линейки реагентов производителя НПК «Химпром», ко- торые представляют композиции аминов, полиамидов и ряда других соединений. Характеристики реагентов приведены в табл. 2.

Все ингибиторы имеют $100 \%$ растворимость в воде и рекомендуемую концентрацию к применению от 0,5 до $3 \%$.

В качестве эталонного образца глины был использован немодифицированный бентонитовый глинопорошок марки ПББ(АМ) производства $\mathrm{OOO}$ «Бентонит Кургана». Данный глинопорошок обладает хорошей способностью набухания и не содержит в своем составе активных компонентов. Параметры глинопорошка приведены в табл. 3 .

Исследование проводилось с помощью модели для измерения линейного набухания глины Linear Swellmeter OFITE. Это прибор, используемый для определения гидратирования или дегидратирования глин и глинистых пород путем измерения изменения линейных размеров образца из глины либо реконструированного или цельного керна. Результаты испытания отображаются в виде графиков, которые показывают степень набухания в процентах от начального размера образца в зависимости от времени [19].

В измерении высоты образца за определённый промежуток времени заключается суть метода, а в основе исследований заложен процесс поглощения дисперсионной среды (жидкости) дисперсной фазой (образцом), сопровождаемый увеличением объема образца при продольном набухании.

Прибор оснащен автоматической электронной измерительной системой. Измерительный преобразователь линейных перемещений (Linear Variable Defferential Transducer - LVDT) измеряет расширение пробы в вертикальном направлении с точностью до $0,1 \%$, и эта информация затем сохраняется как функция от времени через систему обработки информации. С помощью гидравлического компактора образцы неорганических пород спрессовывают в брикет для помещения его в ячейку и последующего исследования.

Четыре ячейки с измерительными головками позволяют одновременно проводить четыре испытания. Полученные данные обрабатываются программой, которая регистрирует изменения и выводит их на экран.

Для эксперимента в каждую ячейку помещался брикет из глинопорошка, спрессованный в гидравлическом компакторе OFITE при давлении 6000 psi, или 41 МПа, что соответствует сжатию породы на глубине около 3500 м. Далее в ячейку с брикетом заливалась исследуемая жидкость. 
Таблица 2. Паспортные характеристики тестируемых ингибиторов

Table 2. Passport characteristics of the tested inhibitors

\begin{tabular}{|c|c|c|c|c|c|}
\hline $\begin{array}{l}\text { Название } \\
\text { реагента } \\
\text { Reagent } \\
\text { name }\end{array}$ & $\begin{array}{l}\text { Общее описание } \\
\text { General description }\end{array}$ & $\begin{array}{l}\text { Назначение } \\
\text { Appointment }\end{array}$ & $\begin{array}{l}\text { Внешний вид } \\
\text { Appearance }\end{array}$ & $\begin{array}{c}t \text { замер- } \\
\text { зания, }{ }^{\circ} \mathrm{C} \\
\text { freezing } \\
t,{ }^{\circ} \mathrm{C}\end{array}$ & $\begin{array}{c}\mathrm{pH}, \\
\text { не менее } \\
\mathrm{pH}, \\
\text { not less }\end{array}$ \\
\hline $\begin{array}{l}\text { Ингидол А } \\
\text { Ingidol A }\end{array}$ & $\begin{array}{l}\text { Концентрат амидов алифатиче- } \\
\text { ского ряда со слабокатионными } \\
\text { свойствами } \\
\text { Aliphatic amide concentrate with } \\
\text { low cationic properties }\end{array}$ & $\begin{array}{l}\text { Ингибитор аргилли- } \\
\text { тов и алевролитов } \\
\text { Inhibitor of mud- } \\
\text { stones and siltstones }\end{array}$ & $\begin{array}{l}\text { Вязкая жидкость от темно- } \\
\text { коричневого до черного цвета } \\
\text { Dark brown to black viscous } \\
\text { liquid }\end{array}$ & -8 & 6 \\
\hline $\begin{array}{l}\text { Ингидол Б } \\
\text { Ingidol B }\end{array}$ & $\begin{array}{l}\text { Композиция природных амидов и } \\
\text { полиэфиров с модифицирующи- } \\
\text { ми добавками } \\
\text { Composition of natural amides and } \\
\text { polyesters with modifying additives }\end{array}$ & $\begin{array}{l}\text { Ингибирование } \\
\text { набухания глини- } \\
\text { стых минералов } \\
\text { Inhibition of clay } \\
\text { mineral swelling }\end{array}$ & $\begin{array}{l}\text { Вязкая жидкость темно- } \\
\text { коричневого цвета } \\
\text { Dark brown viscous liquid }\end{array}$ & -8 & 6 \\
\hline $\begin{array}{l}\text { Terra Hib } \\
\text { AM }\end{array}$ & $\begin{array}{l}\text { Композиция на основе полиами- } \\
\text { нов, амидов и полиэфиров с мо- } \\
\text { дифицирующими добавками } \\
\text { Composition based on polyamines, } \\
\text { amides and polyesters with modify- } \\
\text { ing additives }\end{array}$ & $\begin{array}{l}\text { Ингибитор глин и } \\
\text { глинистых сланцев } \\
\text { Clay and shale } \\
\text { inhibitor }\end{array}$ & $\begin{array}{l}\text { Темно-коричневая жидкость } \\
\text { Dark brown liquid }\end{array}$ & -15 & $6-9$ \\
\hline $\begin{array}{l}\text { Ингидол Sil } \\
\text { Ingidol Sil }\end{array}$ & $\begin{array}{l}\text { Композиция кремнийорганиче- } \\
\text { ских соединений } \\
\text { Composition of organosilicon com- } \\
\text { pounds }\end{array}$ & $\begin{array}{l}\text { Гидрофобизатор, } \\
\text { регулятор реологи- } \\
\text { ческих свойств } \\
\text { Water repellent, regu- } \\
\text { lator of rheological } \\
\text { properties }\end{array}$ & $\begin{array}{l}\text { Прозрачная или слегка мутная } \\
\text { жидкость, от бесцветного до } \\
\text { светло-коричневого цвета, до- } \\
\text { пускается наличие мелкодис- } \\
\text { персного осадка } \\
\text { Clear or slightly cloudy liquid, } \\
\text { from colorless to light brown in } \\
\text { color, a fine precipitate is allowed }\end{array}$ & - & $13-14$ \\
\hline $\begin{array}{c}\text { Ингидол } \\
\text { ГГЛ } \\
\text { Ingidol GGL }\end{array}$ & $\begin{array}{l}\text { Композиция битума и производ- } \\
\text { ных, гильсонита, модифициро- } \\
\text { ванных жирных кислот } \\
\text { Composition of bitumen and deriva- } \\
\text { tives, gilsonite, modified fatty acids }\end{array}$ & $\begin{array}{l}\text { Стабилизация не- } \\
\text { стабильных глин } \\
\text { Stabilization of un- } \\
\text { stable clays }\end{array}$ & $\begin{array}{l}\text { Однородная густая жидкость } \\
\text { от темно-коричневого до чер- } \\
\text { ного цвета } \\
\text { Homogeneous thick liquid from } \\
\text { dark brown to black }\end{array}$ & -30 & - \\
\hline $\begin{array}{c}\text { ГКЖ-11H } \\
\text { GKZH-11N }\end{array}$ & $\begin{array}{l}\text { Концентрированный водный рас- } \\
\text { твор метилсиликоната натрия } \\
\text { Concentrated aqueous solution of } \\
\text { sodium methylsiliconate }\end{array}$ & $\begin{array}{l}\text { Модификатор гли- } \\
\text { нитых буровых рас- } \\
\text { творов } \\
\text { Clay drilling fluid } \\
\text { modifier }\end{array}$ & $\begin{array}{l}\text { Жидкость от бесцветного до } \\
\text { светло-коричневого цвета. } \\
\text { Допускается наличие мелко- } \\
\text { дисперсного осадка и механи- } \\
\text { ческих примесей } \\
\text { Colorless to light brown liquid. } \\
\text { Fine sediment and mechanical } \\
\text { impurities are allowed }\end{array}$ & - & - \\
\hline
\end{tabular}

Таблица 3. Параметры глинопорочка ПББ (АМ)

Table 3. Parameters of $P B B$ clay powder (AM)

\begin{tabular}{|c|c|c|c|c|c|c|}
\hline \multirow[t]{2}{*}{$\begin{array}{l}\text { № Про- } \\
\text { бы } \\
\text { Sample } \\
\text { no. }\end{array}$} & \multirow[t]{2}{*}{$\begin{array}{l}\text { Описание } \\
\text { Description }\end{array}$} & \multirow[t]{2}{*}{$\begin{array}{l}\text { Влага по- } \\
\text { рошка, \% } \\
\text { Powder } \\
\text { moisture, \% }\end{array}$} & \multirow[t]{2}{*}{$\begin{array}{c}\text { Выход глинистого } \\
\text { раствора, } \mathrm{M}^{3} / \mathrm{T} \\
\text { Clay solution yield, } \\
\mathrm{m}^{3} / \mathrm{t}\end{array}$} & \multicolumn{2}{|c|}{$\begin{array}{c}\text { Мокрый ситовый анализ: } \\
\text { остаток на сите с сеткой, \% } \\
\text { Wet sieve analysis: residue on a } \\
\text { sieve with a mesh, \% }\end{array}$} & \multirow[t]{2}{*}{$\begin{array}{l}\text { Фильтрация, } \\
\quad \text { см }^{3} \\
\text { Filtration, } \mathrm{cm}^{3}\end{array}$} \\
\hline & & & & № 05 & № 0071 & \\
\hline 219 & $\begin{array}{c}\text { Глинопорошок бентонито- } \\
\text { вый марки ПББ(АМ) } \\
\text { Bentonite clay powder of } \\
\text { grade PBB (AM) }\end{array}$ & 11,4 & 17,0 & 0,00 & 1,00 & 13,2 \\
\hline
\end{tabular}

На первом этапе приготавливались водные растворы ингибиторов в концентрации 0,5\%. Замер степени набухания брикета производился в течение 1-3 суток при постоянном перемешивании. Кривые набухания для каждого ингибитора приведены на рис. 1.

\section{Результаты исследования и их обсуждение}

На графике рис. 1 видно, что кривые набухания не стабилизировались - процесс гидратации не прекратился по истечении 2 суток. Однако уже можно сделать вывод об ингибирующей способности реагентов. Максимальную степень набухания показал образец в растворе TerraHib AM - $170 \%$ от исходного размера брикета глинопорошка. Лучшую ингибирующую спо- собность продемонстрировал Ингидол ГГЛ - $95 \%$, механизм ингибирования которого заключается в кольматации микротрещин асфальтенами. Также можно отметить и реагент Ингидол Б с близким значениями расширения брикета $107 \%$. Максимальное снижение гидратации происходит за счет механизма ингибирования, который заключается в адсорбции полиаминов на глинистой макроповерхности, Находящиеся в водной фазе промывочной жидкости молекулы ингибитора не коагулируют коллоидную глинистую фазу, так как они электронейтральны.

Результаты линейного набухания брикетов глинопорошка в водных растворах ингибиторов приведены в табл. 4. 


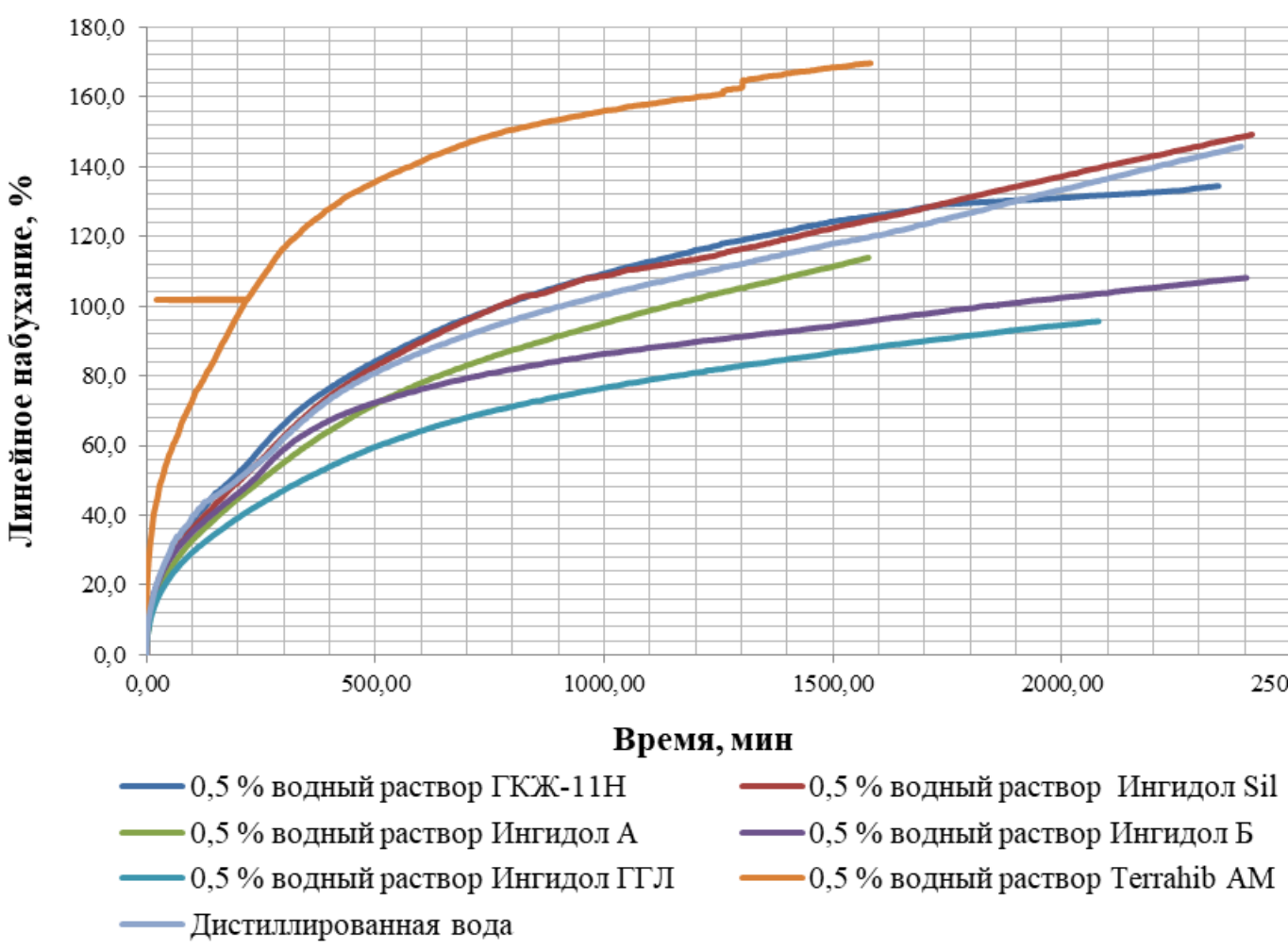

Рис. 1. График набухания образиа в водных растворах ингибиторов

Fig. 1. Graph of sample swelling in aqueous solutions of inhibitors

Таблица 4. Результаты линейного набухания брикета

Table 4. Results of a briquette linear swelling

\begin{tabular}{|l|c|}
\hline \multicolumn{1}{|c|}{$\begin{array}{c}\text { Cpeда } \\
\text { Medium }\end{array}$} & $\begin{array}{c}\text { Paсширение брикета, \% } \\
\text { Briquette expansion, \% }\end{array}$ \\
\hline Ингидол A/Ingidol A & 110 \\
\hline Ингидол Б/Ingidol B & 107 \\
\hline Теrra Нib AM & 170 \\
\hline Ингидол Sil/Ingidol Sil & 147 \\
\hline Ингидол ГГЛ/Ingidol GGL & 95 \\
\hline ГКЖ-11Н/GKZH-11N & 134 \\
\hline
\end{tabular}

Для получения сравнительных данных в лаборатории провели исследования по оценке влияния дистиллированной воды и водных растворов реагентов ингибиторов органических солей $\mathrm{CaCl}_{2}, \mathrm{KCl}, \mathrm{NaCl}$, $\mathrm{MgCl}^{*} 6 \mathrm{H}_{2} \mathrm{O}$ на брикеты из глинопорошка.

Кривые набухания приведены на рис. 2.

Обработанные результаты, полученные по графикам, приведены в табл. 5.

Импрегнирование дистиллированной воды и набухание брикета глинопорошка в начальной стадии происходит медленнее, чем в водных растворах солей, и продолжается по истечении более 170 ч.

На графике видно (рис. 2), что во всех растворах электролитов набухание стабилизировалось после 120 мин. Расширение брикета глинопорошка в $\mathrm{KCl}$ и $\mathrm{CaCl}_{2}$ выше, чем в растворах солей $\mathrm{MgCl} * 6 \mathrm{H}_{2} \mathrm{O}$ и $\mathrm{NaCl}$. Соли калия оказывают разупрочняющее действие на водную структуру, при этом вязкость воды снижается. Скорость проникновения водных растворов солей между глинистыми частицами возрастает, что приводит к большему набуханию (табл. 5).

Соли магния и натрия оказывают упорядочивающее действие на молекулы воды, при этом вязкость водной фазы возрастает, вместе с тем замедляется скорость проникновения водной фазы между частицами глинопорошка (табл. 5).

Таблица 5. Результаты тестирования ингибиторов в LSM OFITE

Table. 5. Inhibitor test results at LSM OFITE

\begin{tabular}{|c|c|}
\hline $\begin{array}{c}\text { Cреда } \\
\text { Medium }\end{array}$ & $\begin{array}{c}\text { Paсширение брикета, \% } \\
\text { Briquette expansion, \% }\end{array}$ \\
\hline $\mathrm{CaCl}_{2}, 5 \%$ & 134 \\
\hline $\mathrm{KCl}, 5 \%$ & 132 \\
\hline $\mathrm{NaCl}, 5 \%$ & 110 \\
\hline $\mathrm{MgCl}^{*} 6 \mathrm{H}_{2} \mathrm{O}, 5 \%$ & 95 \\
\hline $\begin{array}{c}\text { Дистиллированная вода } \\
\text { Distilled water }\end{array}$ & 170 \\
\hline
\end{tabular}

Отсюда следует, что для бурения интервала пластичных монтмориллонитовых глин натриевого типа в испытуемых средах предпочтительнее использовать ингибирующие буровые растворы с содержанием хлорида магния и натрия.

Необходимо учесть, что реагенты-электролиты являются сильными коагулянтами коллоидных систем и их использование в глинистых суспензиях весьма затруднено, поэтому такие типы ингибиторов чаще применяют в безглинистых буровых растворах (например, биополимерный хлоркалиевый раствор) [20].

На втором этапе было выполнено исследование по влиянию реагентов ингибиторов на параметры бурового раствора. Для этого приготавливали пресный глинистый буровой раствор с 0,5 \% содержанием реагента ингибитора. По итогам экспериментов полученные показатели влияния ингибиторов на параметры пресного глинистого бурового раствора сведены в табл. 6. 


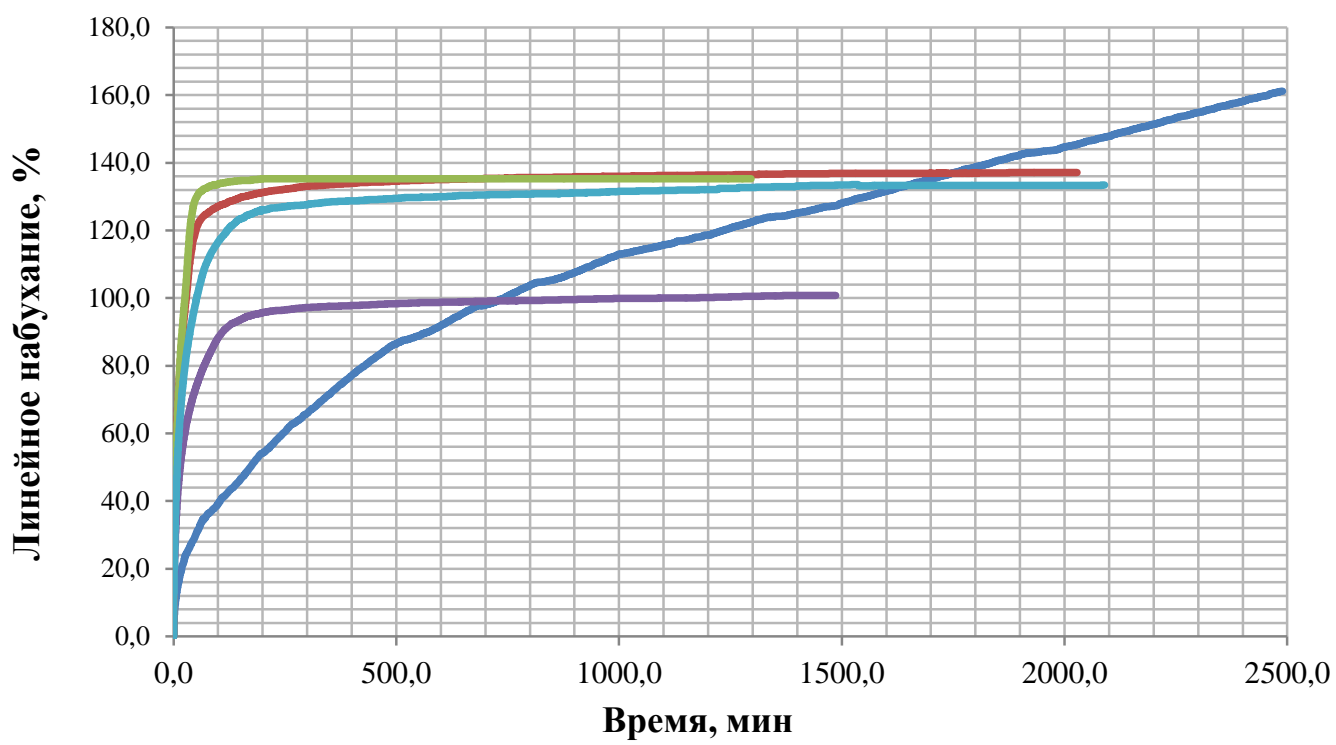

— Дистиллированная вода

$-5 \%$ водный раствор $\mathrm{CaCl} 2$

5 \% водный раствор $\mathrm{KCl}$

$-5 \%$ водный раствор $\mathrm{NaCl}$

5 \% водный раствор $\mathrm{MgCl} 2 \cdot 6 \mathrm{H} 2 \mathrm{O}$

Рис. 2. График набухания образиа в водных растворах солей

Fig. 2. Graph of sample swelling in aqueous solutions of salts

Таблица 6. Результаты замера параметров бурового раствора

Table 6. Drilling fluid measurement results

\begin{tabular}{|c|c|c|c|c|c|c|c|}
\hline \multirow[b]{2}{*}{ Среда/Medium } & \multicolumn{7}{|c|}{ Параметры/Parameters } \\
\hline & $\begin{array}{l}\mathrm{YB}_{700 / 500}, \mathrm{c} \\
\mathrm{FV}_{700 / 500}, \mathrm{~s}\end{array}$ & $\begin{array}{l}\Pi \mathrm{\Pi B}, \mathrm{c} \Pi_{3} \\
\mathrm{PV}, \mathrm{sPz}\end{array}$ & $\begin{array}{l}\text { ДНС, дПа } \\
\text { ҮР, dPa }\end{array}$ & $\begin{array}{c}\mathrm{CHC}_{10 / 10}, \text { дПа } \\
\mathrm{GS}_{10} / 10, \mathrm{dPa}\end{array}$ & $\begin{array}{l}\Phi_{30} \text { по API, } \mathrm{cm}^{3} \\
\mathrm{~F}_{30} \text { by API, } \mathrm{cm}^{3}\end{array}$ & $\begin{array}{l}\mathrm{K}_{\text {лип }} \\
\mathrm{C}_{\text {liр }} \\
\end{array}$ & $\mathrm{pH}$ \\
\hline $\begin{array}{l}\text { Пресный глинистый раствор } \\
\text { Fresh clay }\end{array}$ & $\begin{array}{c}\text { Не течет } \\
\text { Does not flow }\end{array}$ & 1,9 & 246,0 & $282 / 363$ & 15,0 & 0,0437 & 9,84 \\
\hline $\begin{array}{l}\text { Ингидол А } \\
\text { Ingidol A }\end{array}$ & $\begin{array}{c}\text { Не течет } \\
\text { Does not flow }\end{array}$ & 2,4 & 260,0 & $289 / 486$ & 17,2 & 0,0480 & 9,83 \\
\hline $\begin{array}{l}\text { Ингидол Б } \\
\text { Ingidol В }\end{array}$ & 27,4 & 6,0 & 78,0 & $145 / 306$ & 13,0 & 0,0393 & 9,74 \\
\hline Terra Hib AM & $\begin{array}{c}\text { Не течет } \\
\text { Does not flow }\end{array}$ & 0,3 & 434,0 & $330 / 278$ & 19,0 & 0,0480 & 9,15 \\
\hline $\begin{array}{l}\text { Ингидол Sil } \\
\text { Ingidol Sil } \\
\end{array}$ & 33,4 & 9,6 & 57,0 & $54 / 53$ & 23,5 & 0,0393 & 9,96 \\
\hline $\begin{array}{l}\text { Ингидол ГГЛ } \\
\text { Ingidol GGL }\end{array}$ & 75,8 & 2,4 & 198,0 & $256 / 459$ & 17,0 & 0,0437 & 9,78 \\
\hline $\begin{array}{l}\text { ГКЖ-11H } \\
\text { GKZH-11N }\end{array}$ & 42,8 & 18,4 & 61,0 & $140 / 249$ & 18,5 & 0,0262 & 9,81 \\
\hline
\end{tabular}

Примечание: УВ - условная вязкость; ПВ - пластическая вязкость; ДНС-динамическое напряжение сдвига; СНС -

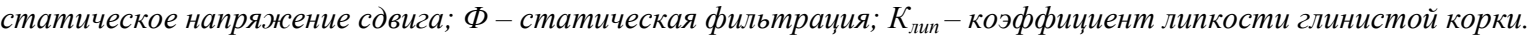

Note: $F V_{700 / 500}$ - funnel viscosity; PV - plastic viscosity; YP - yield point; GS 10 10-gel strengths (for 10 seconds and 10 minutes); $F_{30}$ by API - filtration for 30 minutes by API; $C_{\text {lip }}$ - stickiness coefficient; $p H$ - hydrogen ion exponent.

В целом по данным табл. 6 можно отметить, что реагенты Ингидол Б, Ингидол Sil, ГКЖ-11Н, Ингидол ГГЛ активно разжижают буровой раствор.

Ингибитор Индинол А интенсивно загущает буровой раствор, увеличивая при этом показатели динамического напряжения сдвига и фильтрации. Данный ингибитор в большей степени предназначен для скважин, сложенных аргиллитоподобными и алевролитистыми отложениями.

Экспериментально установлено, что добавление Индинол Б в пресный глинистый буровой раствор способствует его разжижению, снижению реологических и фильтрационных свойств. Усиление ингиби- рующего эффекта связано с повышением молекулярной массы полимера. Полимеры создают водные сетки с молекулами воды и скрепляют частицы глины.

Органический ингибитор Terra Hib AM на основе поламинов в глинистых системах не работоспособны. Добавка снижает пластическую вязкость практически до нулевых значений, при этом степень ингибирования остается равной исходному раствору $170 \%$ (табл. 4, 5).

Реагент на основе кремнийорганических соединений Ингидол Sil является сильным разжижителем бурового раствора, при его введении в раствор наблюдалось повышение показателя фильтрации и резкое 
снижение структурно-механических и реологических свойств.

Из всех вышеперечисленных ингибирующих добавок только Ингидол ГГЛ значительно снижает расширение кернового материала 95 \%. Он изготовлен на основе битума и производных гильсонита, что положительно сказалось на закупоривающих свойствах раствора.

При введении в буровой раствор кремнийорганической соли метилсиликоната натрия ГКЖ-11Н раствор разжижается, снижаются структурнореологические параметры, повышается фильтрация. ГКЖ-11Н, так же как и Ингидол Sil, показал повышенные значения расширения кернового материала на $134 \%$.

\section{Заключение}

В результате проведенных исследований установлено:

\section{СПИСОК ЛИТЕРАТУРЫ}

1. Булатов А.И., Макаренко П.П., Проселков Ю.М. Буровые промывочные и тампонажные растворы. - М.: Недра, 1999. $424 \mathrm{c}$.

2. Грей Дж.Р., Дарли Г.С.Г. Состав и свойства буровых агентов (промывочных жидкостей). - М.: Недра, 1985. - 509 с

3. Устойчивость пород при бурении скважин / М.М.-Р. Гайдаров, А.Д. Норов, А.А. Хуббатов, А.И. Иванов, А.М. Гайдаров, Ю.М. Богданова, С.А. Кравцов, И.Г. Поляков, Г.Б. Касымов // Строительство нефтяных и газовых скважин на суше и на моpe. -2013 . - № 7. - C. $20-30$

4. Булатов А.И., Пеньков А.И., Проселков Ю.М. Справочник по промывке скважин. - М.: Недра, 1984. - 317 с.

5. Белоруссов В.О. Технология борьбы с осложнениями при бурении скважин. - М.: Недра, 1967. - 162 с

6. Mahto V., Sharma V. Rheological study of a water based oil well drilling fluid // Journal of Petroleum Science and Engineering. 2004. - V. 45. - Iss. 1-2. - P. 123-128.

7. Ibelegbu Ch. Productivity index in horizontal wells // Journal of Scientific \& Industrial Research. - 2004. - № 63. - P. 979-984.

8. Исследование влияния состава эмульсионных буровых растворов на их показатели / А.И. Ламбин, В.М. Иванишин, Р.У. Сираев, Е.В. Аверкина, Э.В. Шакирова, А.В. Коротков // Известия Сибирского отделения Секции наук о Земле Российской академии естественных наук. Геология, поиски и разведка рудных месторождений. - 2015. - № 4 (53). - С. 58-66.

9. Применение нефти в качестве смазочной добавки в буровом растворе (на примере Ярактинского нефтегазоконденсатного месторождения) / Э.В. Шакирова, Е.В. Аверкина, Т.Р. Сабиров, К.О. Перышкина // Нефтегазовое дело. - 2018. - Т. 16. № 2. - C. 12-19.

10. Применение ингибирующих композиций органического и неорганического типа / В.Н. Сас, И.В. Панов, Р.О. Кожевников, Е.Я. Мелешко // Бурение и нефть. - 2017. - № 12. - С. 30-33.
1) Соли $\mathrm{MgCl} * 6 \mathrm{H}_{2} \mathrm{O}$ и $\mathrm{NaCl}$, структурирующие молекулы воды, снижают набухание глинопорошка.

2) Среди органических реагентов лучший результат по ингибированию набухания в концентрации 0,5 \% показали реагенты Ингидол ГГЛ и Ингидол Б.

3) При введении в глинистый раствор органических игибиторов на основе кремнийорганических композиций и природных аминов наблюдалось его активное разжижение.

4) Все образцы ингибиторов в разной степени оказывают влияние на параметры бурового раствора, наиболее благоприятными для использования в пресном глинистом буровом растворе на основе бентонитовой немодифицированной глины оказались Ингидол Б и Ингидол Sil. Остальные образцы также могут успешно использоваться при дальнейшей обработке раствора для регулирования реологических параметров и показателя фильтрации после проведенных дополнительных исследований.

11. Henriksen K.H., Gule E.I., Augustine J. Case study: the application of inflow control devices in the troll oil field // SPE100308-SM. Annual conference and exhibition. - Vienna, Austria, 12-15 June 2006. - P. 1-5.

12. Fink J. Petroleum engineers guide to oil field chemicals and fluids. Waltham, MA: Gulf Professional Publ., 2011. - 808 p.

13. Akangbou H.N., Burby M.L., Nasr G.G. Effectively optimizing production of horizontal wells in homogeneous oil reservoirs // Journal of Petroleum Science and Engineering. - 2017. - № 11. C. $59-62$.

14. Особенности набухания глин в растворах электролитах / Г.М. Панахов, Э.М. Аббасов, А.О. Юзбашиева, В.Д. Балакчи // Нефтегазовое дело. - 2019. - № 4. - С. 93-109.

15. Tarek A. Ganatana, Meftah Hrairi. A new choke correlation to predict flow rate of artificially flowing wells // Journal of Petroleum Science and Engineering. - 2018. - V. 171. - P. 1378-1389.

16. Чудинова И.В., Николаев Н.И. Разработка состава и исследование свойств бурового раствора для бурения скважин в неустойчивых глинистых породах // Успехи современного естествознания. -2019 . - № 8. - С. 85-89.

17. Numerical determination of strength and deformability of fractured rock mass by FEM modeling / J. Yang, W. Chen, D. Yang, J. Yuan // Computers and Geotechnics. - 2015. - V. 64. P. 20-31.

18. Horizontal drilling - a new production method / J.C. Bosio, R.W. Fincher, J.F. Giannesini, J.L. Hatten // XII World Petroleum Congress. - USA, 1987. - P. 18-22.

19. Дегтярев Д.Ф. Оценка воздействия минерального и органического ингибиторов на бентонитовую глину // Георесурсы. 2018. - T. 20. - № 4. - C. 355-358.

20. Moritis G. Worldwide horizontal drilling surges // Oil and gas journal. - 1989. - V. 87 (9). - P. 53-64.

Поступила 18.11.2020 2.

\section{Информация об авторах}

Аверкина E.B., старший преподаватель кафедры нефтегазового дела Института недропользования Иркутского национального исследовательского технического университета.

Шакирова Э.В., кандидат политических наук, доцент кафедры нефтегазового дела Института недропользования Иркутского национального исследовательского технического университета.

Николаева М.Б., магистр Института геологии и нефтегазовых технологий Казанского федерального университета.

Климова $\boldsymbol{A}$.А., младший научный сотрудник лаборатории буровых растворов и крепления скважин кафедры нефтегазового дела Института недропользования Иркутского национального исследовательского технического университета. 
UDC 662.24 .06

\title{
COMPARATIVE ANALYSIS OF REAGENTS-INHIBITORS OF SWELLING OF CLAY DEPOSITS USED IN EASTERN SIBERIA
}

\author{
Elena V. Averkina ${ }^{1}$, \\ averkina.|@yandex.ru
}

\section{Elvira V. Shakirova1 viva160@mail.ru}

\section{Margarita B. Nikolaeva², margaritanik97@mail.ru}

\author{
Aina A. Klimova ${ }^{1}$, \\ cherdanceva94@yandex.ru \\ 1 Irkutsk National Research Technical University, \\ 83, Lermontov street, Irkutsk, 664074, Russia. \\ 2 Kazan Federal University, \\ 18, Kremlevskaya street, Kazan, 420008, Russia.
}

The relevance. The subsalt structural complex of Eastern Siberian deposits includes Ordovician deposits, which are mainly represented by sandy loams, loams, clays, siltstones, marls and dolomites. The subsalt complex consists of mudstones, dolomites, limestones, as well as their intercalation. When drilling oil wells, a large number of complications can cause swelling of clay rocks: sticking of a drilling tool, cavern formation, gland formation, expansion of the wellbore, loss of circulation, etc. The drilling fluid must have a high inhibitory ability to minimize the swelling rate.

The main aim of the research is to study the inhibiting property of reagents, which represent compositions of amines, polyamides and some other compounds.

Object: drilling fluid used in the fields of Eastern Siberia.

Methods. To define the linear swelling of clay the authors have used the Linear Swellmeter OFITE model, which determines the hydration or dehydration of clays and clay rocks by measuring the change in the linear dimensions of the clay sample. The effect of inhibitor reagents on drilling fluid rheological parameters was studied using traditional methods.

Results. It was found that $\mathrm{MgCl}{ }^{*} 6 \mathrm{H}_{2} \mathrm{O}$ and $\mathrm{NaCl}$ salts, which structure water molecules, reduce the swelling of clay powder. All the studied inhibitor samples to varying degrees affect the parameters of the drilling fluid, Ingidol B and Ingidol Sil were the most favorable for use in fresh clay drilling mud based on unmodified bentonite clay. The remaining samples can also be successfully used during further processing of the solution to control the rheological parameters and the filtration index after additional studies.

\section{Key words:}

Drilling mud, inhibitors, clay deposits, Eastern Siberia, rheological properties.

\section{REFERENCES}

1. Bulatov A.I., Makarenko P.P., Proselkov Yu.M. Burovye promyvochnye $i$ tamponazhnye rastvory [Drilling flushing and grouting solutions]. Moscow, Nedra Publ., 1999. 424 p.

2. Gray J.R., Darley G.S.G. Sostav $i$ svoystva burovykh agentov [Composition and properties of drilling agents (flushing fluids)]. Moscow, Nedra Publ., 1985. 509 p.

3. Gaydarov M.M.-R., Norov A.D., Khubbatov A.A., Ivanov A.I Gaydarov A.M., Bogdanova Yu.M., Kravtsov S.A., Polyakov I.G., Kasymov G.B. Ustoychivost porod pri burenii skvazhin [Stability of rocks during well drilling]. Stroitelsvo neftyanykh i gazovykh skvazhin na sushe i na more, 2013, no. 7, pp. 20-30.

4. Bulatov A.I., Penkov A.I., Proselkov Yu.M. Spravochnik po promyvke skvazhin [Guide to flushing wells]. Moscow, Nedra Publ., 1984. 317 p.

5. Belarus V.O. Tekhnologiya borby s oslozhneniyami pri bureni skvazhin [Technology for dealing with complications when drilling wells]. Moscow, Nedra Publ., 1967. 162 p.

6. Mahto V., Sharma V. Rheological study of a water based oil well drilling fluid. Journal of Petroleum Science and Engineering, 2004, vol. 45, Iss. 1-2, pp. 123-128

7. Ibelegbu Ch. Productivity index in horizontal wells. Journal of Scientific \& Industrial Research, 2004, no. 63, pp. 979-984.

8. Lambin A.I., Ivanishin V.M., Siraev R.U., Averkina E.V., Shakirova E.V., Korotkov A.V. Investigation of the effect of the composition of emulsion drilling fluids on their performance. Proceedings of the Siberian Branch of the Section of Earth Sciences of the
Russian Academy of Natural Sciences. Geology, prospecting and exploration of ore deposits, 2015, no. 4 (53), pp. 58-66. In Rus.

9. Shakirova E.V., Averkina E.V., Sabirov T.R., Peryshkina K.O. The use of oil as a lubricant in a drilling fluid (for example, the Yarakta oil and gas condensate field). Oil and gas business, 2018, vol. 16, no. 2, pp. 12-19. In Rus.

10. Sas V.N., Panov I.V., Kozhevnikov R.O., Meleshko E.Ya. The use of inhibitory compositions of organic and inorganic type. Drilling and oil, 2017, no. 12, pp. 30-33. In Rus.

11. Henriksen K.H., Gule E.I., Augustine J. Case study: the application of inflow control devices in the troll oil field. SPE-100308-SM Annual conference and exhibition. Vienna, Austria, 12-15 June 2006. pp. 1-5.

12. Fink J. Petroleum engineers guide to oil field chemicals and fluids. Waltham, MA, Gulf Professional Publ., 2011. 808 p.

13. Akangbou H.N., Burby M.L., Nasr G.G. Effectively optimizing production of horizontal wells in homogeneous oil reservoirs. Journal of Petroleum Science and Engineering, 2017, no. 11, pp. 59-62.

14. Panakhov G.M., Abbasov E.M., Yuzbashieva A.O., Balakchi V.D. Features of clay swelling in electrolyte solutions. Oil and gas business, 2019, no. 4, pp. 93-109. In Rus.

15. Tarek A. Ganatana, Meftah Hrairi. A new choke correlation to predict flow rate of artificially flowing wells. Journal of Petroleum Science and Engineering, 2018, vol. 171, pp. 1378-1389.

16. Chudinova I.V., Nikolaev N.I. Development of the composition and study of the properties of drilling mud for drilling wells in un- 
stable clay rocks. Uspekhi sovremennogo estestvoznaniya, 2019 no. 8, pp. 85-89. In Rus.

17. Yang J., Chen W., Yang D., Yuan J. Numerical determination of strength and deformability of fractured rock mass by FEM modeling. Computers and Geotechnics, 2015, vol. 64, pp. 20-31.

18. Bosio J.C., Fincher R.W., Giannesini J.F., Hatten J.L. Horizontal drilling - a new production method. XII World Petroleum Congress. USA, 1987. pp. 18-22.

Information about the authors

Elena V. Averkina, senior lecturer, Irkutsk National Research Technical University.

Elvira V. Shakirova, Cand Sc., associate professor, Irkutsk National Research Technical University.

Margarita B. Nikolaeva, master, Kazan Federal University.

Aina A. Klimova, junior researcher, Irkutsk National Research Technical University.
19. Degtyarev D.F. Evaluation of the effect of mineral and organic inhibitors on bentonite clay. Geo-resources, 2018, vol. 20, no. 4. pp. 355-358. In Rus.

20. Moritis G. Worldwide horizontal drilling surges. Oil and gas journal, 1989, vol. 87(9), pp. 53-64.

Received: 18 November 2020. 